\title{
Apicidin Induces Apoptosis via Cytochrome c-Mediated Intrinsic Pathway in Human Ovarian Cancer Cells
}

\author{
Mee Young AHN ${ }^{1}$, Yong Jin $\mathrm{NA}^{2}$, Jaewon LeE ${ }^{1}$, Byung Mu LeE ${ }^{3}$, and Hyung Sik Kıм ${ }^{1, *}$ \\ ${ }^{1}$ College of Pharmacy, ${ }^{2}$ Department of Obstertrics and Gynecology, College of Medicine, Pusan National University, \\ Busan 609-735, ${ }^{3}$ Division of Toxicology, College of Pharmacy, Sungkyunkwan University, Suwon 440-746, Republic of Korea
}

(Received November 7, 2008; Revised January 6, 2009; Accepted January 20, 2009)

\begin{abstract}
Histone deacetylase (HDAC) inhibitors are a promising class of anticancer agents that inhibit cancer cell growth in vitro and in vivo. Previous report has shown that apicidin inhibited SK-OV-3 cells proliferation and down-regulation of cyclin B1 and CDK1, and up-regulation of p21 ${ }^{\text {WAF1 }}$ and p27. However, the mechanism of apicidin-mediated apoptotic cell death is not clearly understood. For this study, we investigated the mechanism of apoptotic pathway induced by apicidin in human ovarian cancer cell. We found that SK-OV-3 cells treated with apicidin caused an increase in the percentage of cells in the G2/M phase, which preceded apoptosis characterized by the appearance of cells with sub-G1 population. To further investigate the mechanism of apoptosis induction by apicidin, we measured TUNEL assay, poly-ADP ribose polymerase (PARP) cleavage, and caspase activity in SK-OV-3 cells treated with apicidin for $48 \mathrm{~h}$. Apicidin significantly enhanced apoptosis as measured by TUNEL positive apoptotic cells, PARP cleavage, and increased Bax/Bcl-2 ratio. Induction of apoptosis was confirmed by the release of cytochrome $c$ to cytosol. Our data suggest that apicidin-induced apoptosis in SK-OV-3 cells was accompanied by caspase-3 activation and the increase in Bax/Bcl-2 ratio. These data suggest that apicidin may be effective in the treatment of ovarian cancer through activation of intrinsic apoptotic pathway.
\end{abstract}

Keywords: Histone deacetylase inhibitor, Apicidin, Ovarian cancer, Apoptosis

\section{INTRODUCTION}

Ovarian epithelial cancer is the most common type of cancer in women with gynecological malignancies, and the incidence is increasing continuously throughout the world (American Cancer Society, 2007). The high mortality rate of ovarian cancer is believed to be due to the detection of disease at an advanced clinical stage when metastatic potential is already high resulting in a poor prognosis (Naora and Montell, 2005). Recently, novel drugs for treatment of advanced gynecological cancer have been investigated for their potential use in chemotherapeutic intervention. Among them, histone deacetylase (HDAC) inhibitors are a promising new class of anti-cancer agents that act through a variety of mechanisms including the induction of cell cycle arrest, morphological reversion of transformed cells, growth inhibition, differentiation, and programmed cell

${ }^{*}$ Corresponding author

Tel: +82-51-510-2816 Fax: +82-51-582-2816

E-mail: hkims@pusan.ac.kr death (Marks et al., 2004; Liu et al., 2006). Histone deacetylation alters local chromatin structure and is one of the major steps in the epigenetic regulation of gene expression (Kim et al., 2006). The net level of histone acetylation is regulated by the balance between the opposing activities of histone acetytransferases (HATs) and HDACs. Disruption of the balance between HDAC and HAT activities can result in cancer (Toh et al., 2003). Several lines of evidence suggest that pharmacological re-equilibration of cellular histone acetylation, generally through HDAC inhibition; can reprogram the epigenetic state of cancer cells by causing histone hyperacetylation. This event ultimately results in the transcriptional activation of specific genes (Xu et al., 2007).

Apicidin isolated from Fusarium $s p$. was first reported to be a reversible inhibitor of the in vitro development of Apicomplexan parasites. Apicidin acts by inhibiting the HDAC enzyme of the parasite, and it was later shown to have anti-proliferative and cyto-differentiation activity on mammalian cells (Mogal and Abdulkadir, 2006). Apicidin 
inhibits the proliferation of several human cancer cell lines, including those derived from leukemias, cervical cancers, ovarian cancers, and breast cancers (Han et al., 2000; Kwon et al., 2002; Ueda et al., 2007; Im et al., 2008). However, the precise mechanism of apicidin-induced apoptotic cell death pathway in human ovarian cancer cells is poorly understood. Herein, we evaluated the effects of apicidin on apoptotic cells death in human ovarian carcinoma cells. In particular, we focused the mechanism of apicidin-induced apoptotic pathway by analyzing the TUNEL assay, caspases activation, and cytochrome $c$ release to cytosol.

\section{MATERIALS AND METHODS}

\section{Chemicals}

Unless stated otherwise, apicidin [cyclo(N-O-methyl-L-tryptophanyl-L-isoleucinyl-D-pipecolinyl-L-2-amino8-oxodecanoyl)] and all chemicals were purchased from Sigma (St. Louis, MO). Apicidin was dissolved in sterile DMSO to yield a $5 \mathrm{mM}$ stock solution which was stored at $-80^{\circ} \mathrm{C}$. Subsequent dilutions were made in RPMI- 1640 .

\section{Cell line and culture}

The SK-OV-3 human epithelial ovarian cancer cell line was purchased from the American Type Culture Collection (Manassas, VA) and was maintained in a humidified atmosphere at $37^{\circ} \mathrm{C}$ in $5 \% \mathrm{CO}_{2}$. The cells were grown in RPMI-1640 (Gibco ${ }^{\circledR}$ Invitrogen Corporation, Carlsbad, CA) media containing $10 \%$ heat-inactivated fetal bovine serum (FBS), $1.25 \mathrm{mM} \mathrm{HEPES}$ and 1\% penicillin/streptomycin.

\section{Cell viability}

Cell growth was quantified using 3-(4,5-dimethylthiazol2-yl)-2,5-diphenyltetrazolium bromide (MTT, $5 \mathrm{mg} / \mathrm{ml}$ ) dissolved in phosphate-buffered saline (PBS). The cultures were initiated in 96-well plates at a density of $1 \times 10^{4}$ cells per well. Cells were allowed to attach for $48 \mathrm{~h}$ before exposure to apicidin. At the end of the treatment period, $15 \mu \mathrm{l}$ of the MTT reagent was added to each well. After $4 \mathrm{~h}$ incubation at $37^{\circ} \mathrm{C}$, the supernatant was aspirated, and formazan crystals were dissolved in $100 \mu \mathrm{LMSO}$ at $37^{\circ} \mathrm{C}$ for 10 min with gentle agitation. The absorbance per well was measured at $540 \mathrm{~nm}$ with a VERS Amax Microplate Reader (Molecular Devices Corp.).

\section{Protein preparation and Western blot analysis}

The cells were washed twice in PBS, suspended in a lysis buffer [ $50 \mathrm{mM}$ Tris (pH 8.0), $150 \mathrm{mM} \mathrm{NaCl}, 0.1 \%$ SDS,
$0.5 \%$ sodium deoxycholate, $1 \%$ nonidet P-40 (NP-40), 100 $\mu \mathrm{g} / \mathrm{ml}$ phenylmethylsulfonyl fluoride (PMSF), $2 \mu \mathrm{g} / \mathrm{ml}$ aprotinin, $1 \mu \mathrm{g} / \mathrm{ml}$ pepstatin, and $10 \mu \mathrm{g} / \mathrm{ml}$ leupeptin], and placed on ice for $30 \mathrm{~min}$. The suspension was collected after centrifugation at $15,000 \times \mathrm{g}$ for $15 \mathrm{~min}$ at $4^{\circ} \mathrm{C}$. Protein concentrations were quantified using the Bio-Rad protein Assay Reagent (Bio-Rad Laboratories, Hercules, CA) according to the manufacturer's instructions. The whole cell lysates $(50 \mu \mathrm{g})$ were resolved on SDS-polyacrylamide gel in a $6-15 \%$ gel, transferred to a polyvinylidene difluoride (PVDF) membrane (NEN life Science, Boston), and probed sequentially with antibodies against PARP (Santa Cruz), Bcl-2 (Santa Cruz), Bax (Santa Cruz), and $\beta$-actin (Sigma, St. Louis, MO). The blots were developed using an enhanced chemiluminescence (ECL) kit (Amersham, Cardiff, UK).

\section{Flow cytometry analysis}

The SK-OV-3 cells were exposed to apicidin for $48 \mathrm{~h}$. The total number of cells, both in suspension and adhered to the wells, were collected, washed, and suspended in cold PBS. The cells were fixed in chilled $75 \%$ methanol and stained with a propidium iodine (PI) solution (100 $\mu \mathrm{g} / \mathrm{ml}$ RNase and $10 \mu \mathrm{g} / \mathrm{ml} \mathrm{PI}$ in PBS). Data acquisition and analysis was performed using a FACScan flow cytometry system (Becton Dickinson, San Jose, CA).

\section{TUNEL assay}

The SK-OV-3 cells were grown on coverslips at a density of $5 \times 10^{4}$ cells per well in a 24-well plate. After the apicidin treatment, apoptosis was detected using an ApopTag In Situ Apoptosis Detection kit (Chemicon international, Temecula, CA) and propidium iodide (PI) staining. The cells were observed using confocal laser scanning microscopy (TCS SP2, Leica, Wetzler, Germany).

\section{Caspases activity assay}

The cultures were initiated in 6-well plates at a density of $1 \times 10^{5}$ cells per well. Cells were allowed to attach for $48 \mathrm{~h}$ and exposed to apicidin for $48 \mathrm{~h}$. The caspase- $3,-8$ and -9 activities in the cell lysate was determined using colorimetric assay kits (Biovision, CA, U.S.A.). Fifty microliters of cell lysate (cytosolic extracts, $100 \mu \mathrm{g}$ ) was incubated with $50 \mu \mathrm{l}$ of $2 \mathrm{x}$ reaction buffer and $2 \mu \mathrm{l}$ of substrates (DEVD-pNA for caspase-3, IETD-pNA for caspase-8 and LEHD-pNA for caspase-9) at $37^{\circ} \mathrm{C}$ for $2 \mathrm{~h}$. After incubation, the chromophores were quantified spectrophotometrically at a wavelength of $405 \mathrm{~nm}$ (Ding et al., 2000). 


\section{Cytochrome c immunofluorescence}

After SK-OV-3 cells were exposed to apicidin for $48 \mathrm{~h}$, the cells were washed with serum-free media and fixed with $3.7 \%$ formaldehyde in serum-free media at $37^{\circ} \mathrm{C}$ for $15 \mathrm{~min}$. Fixed cells were blocked with $5 \%$ normal goat serum in PBS containing $0.2 \%$ Triton $\mathrm{X}-100$ (TPBS) for $1 \mathrm{~h}$ at room temperature to reduce nonspecific labeling. The samples were then incubated for $1 \mathrm{~h}$ at room temperature with $1 \mu \mathrm{g} / \mathrm{ml}$ of primary monoclonal antibody against cytochrome c (Laboratory Vision, Fremont, CA) in PBS with $5 \%$ goat serum. After washing with TPBS, FITC-conjugated secondary antibody (1:200, Molecular Probes, Eugene, OR) was applied for $1 \mathrm{~h}$ in a dark chamber. Nuclear staining was achieved by PI $2.5 \mu \mathrm{g} / \mathrm{ml}$ (Sigma) for $10 \mathrm{~min}$. The samples were then washed with TPBS, covered with an antifade solution and coverslips. A sample treated without the primary antibody was used as the negative control. Digital images were captured using an laser-scanning confocal microscope (TCS SP2, Leica).

\section{Statistical analysis}

All the data is represented as the average of the values obtained \pm SD. Significance was determined using a paired Student's $t$-test. A $p$-value $<0.01$ was considered statistically significant.

\section{RESULTS}

\section{Apicidin inhibits ovarian cancer cell proliferation}

Apicidin has been reported to inhibit the proliferation of a variety of cancer cell lines (Han et al., 2000; Kim et al.,

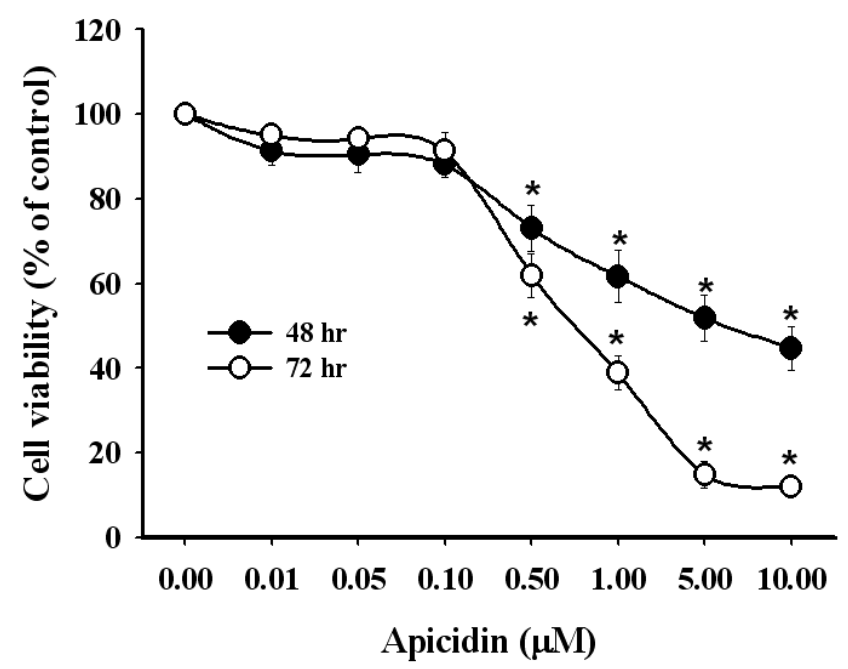

Fig. 1. The effect of apicidin on cell proliferation in SK-OV-3 cells. SK-OV-3 cells were treated with apicidin at various concentrations $(0.01-10 \mu \mathrm{M})$ for the indicated times. Proliferation was measured by MTT assay. The percentage of viable cells was calculated as a ratio of the treated to control cells. The data is expressed as the mean \pm SD of three independent experiments. ${ }^{*} p<0.05$ as determined by a Student's $t$ test.
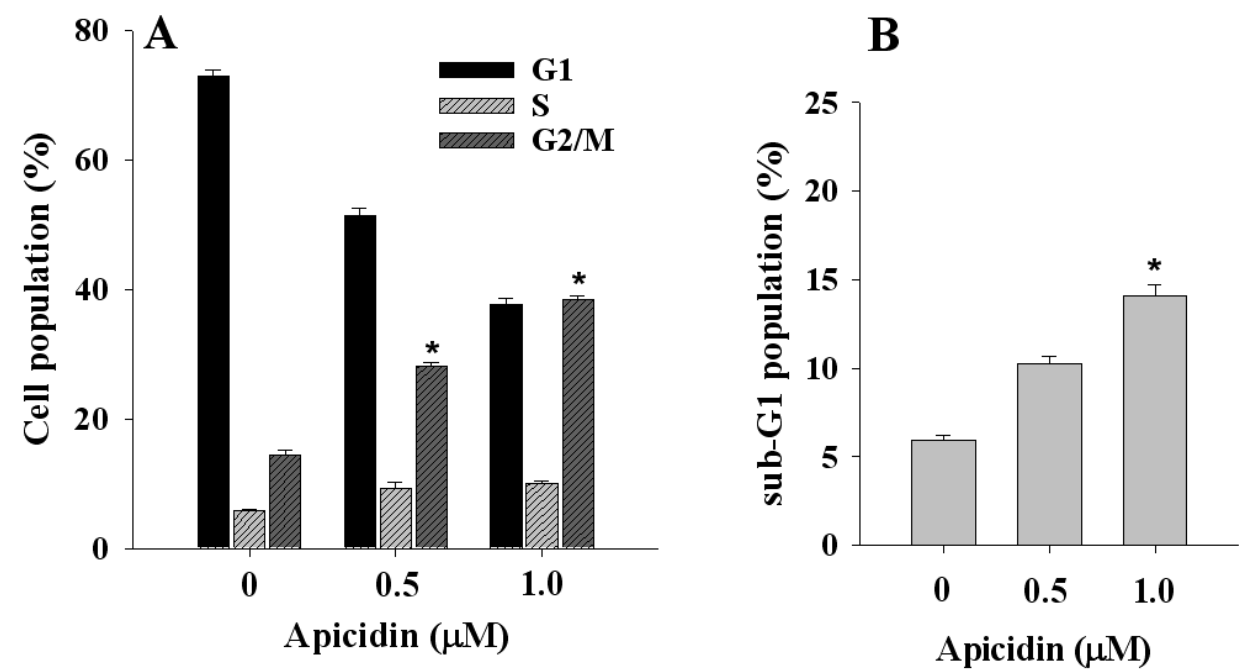

Fig. 2. Cell cycle analysis of apicidin-treated SK-OV-3 cells. (A) SK-OV-3 cells were treated with the indicated concentrations of apicidin for $48 \mathrm{~h}$. The cells were stained with propidium iodine (PI) and subjected to flow cytometry analysis to determine the cell cycle distributions. The fraction of cells in each phase of the cell cycle is presented as the mean $\pm S D$ of three independent experiments. (B) Apicidin induces sub-G1 populations of SK-OV-3 cells. Cells were stained with propidium iodide and sub-G1 DNA contents were analyzed by flow cytometry at $48 \mathrm{~h}$ after apicidin treatment. Results are presented as means \pm SD of triplicate experiments. ${ }^{*} p<0.05$ as determined by a Student's $t$ test. 
2000; Ueda et al., 2007). To determine if apicidin has anticancer activity on human ovarian cancer cells, we treated SK-OV-3 cells with varying doses of the drug for 48 or $72 \mathrm{~h}$ and measured cell viability with MTT assay. Apicidin inhibited the proliferation of SK-OV-3 cells in a concentration-dependent manner, and significant inhibition was observed even at the lowest concentration $(0.5 \mu \mathrm{M})$ after $72 \mathrm{~h}$ of treatment (Fig. 1). This dose-response curve indicates that the $\mathrm{IC}_{50}$ value of apicidin is $0.87 \mu \mathrm{M}$ at $48 \mathrm{~h}$.

\section{Apicidin increases the proportion of cells in the G2/M phase}

We next wished to investigate the effect of apicidin on the cell cycle progression of SK-OV-3 cells. The cells were treated with apicidin at concentrations up to $1.0 \mu \mathrm{M}$ for 48 $\mathrm{h}$, and cell cycle progression was monitored by flow cytometry. Apicidin induced the arrest of SK-OV-3 cells at the G2/M phase of the cell cycle with a concomitant de- crease in the percentage of cells in the G1 phase. SK-OV-3 cells cultured in the presence of $1.0 \mu \mathrm{M}$ apicidin had $38 \%$ of cells in the G2/M phase, compared to only $14 \%$ of the untreated control cells were in the G2/M phases (Fig. 2A). Moreover, at a higher concentration (1.0 $\mu \mathrm{M})$, apicidin significantly induced apoptosis, characterized by the appearance of cells population with sub-G1 (Fig. 2B).

\section{Apicidin regulates the expression of apoptosis-related genes}

To asses whether the growth inhibitory effects of apicidin were associated with the induction of apoptosis, we used an ApopTag (TUNEL) assay and monitored TUNEL positive cells by confocal microscopy. Apicidin significantly increased the number of TUNEL positive apoptotic cells compared with the untreated control (Fig. 3A). Furthermore, treatment of SK-OV-3 cells with apicidin (0.5 and 1.0 $\mu \mathrm{M})$ for $48 \mathrm{~h}$ markedly increased cleavage of PARP, a
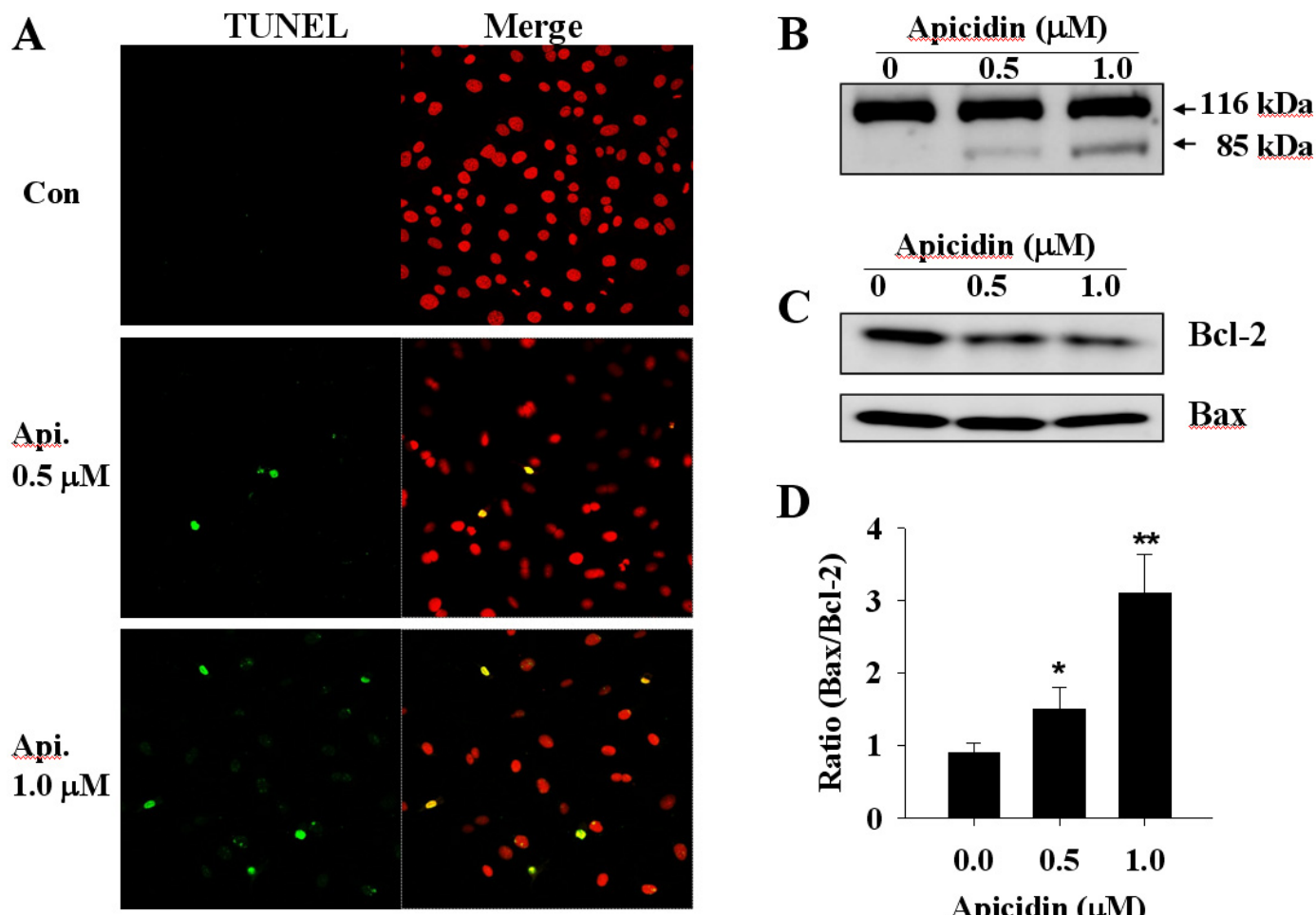

Apicidin $(\mu \mathrm{M})$

Fig. 3. Apicidin induces apoptosis in SK-OV-3 cells. (A) TUNEL assay for apoptotic cells. SK-OV-3 cells were seeded onto sterile coverslips in 24-well plate in medium containing apicidin and grown for $48 \mathrm{~h}$. Apoptotic cells were detected using ApopTag In Situ Apoptosis Detection kits, and the results are shown as a confocal microscopy image (200X magnification). The data shown are representative of two independent experiments. (B) Immunoblot analysis of PARP protein levels. SK-OV-3 cells were treated with the indicated concentrations of apicidin for $48 \mathrm{~h}$. Total cell lysates were prepared and subjected to SDS-PAGE followed by Western blot analysis and chemiluminescent detection. Western blots were performed with an antibody directed against PARP. (C) The expression levels of the Bcl-2 and Bax proteins were determined by Western blotting using specific antibodies. (D) The ratio of Bax to Bcl-2 protein expression was determined from five separate experiments by comparing the relative intensities of protein bands. Data are presented as the mean $\pm \mathrm{SD}$. values of $\mathrm{Bcl}-2 /$ Bax ratio. ${ }^{*} p<0.05$; ${ }^{* *} p<0.01$ as determined by a Student's $t$ test. 
known endogenous substrate for caspases, which play key roles in apoptosis (Fig. 3B). Together these data strongly suggest that apicidin induces apoptosis in SKOV-3 cells in a concentration-dependent manner. To determine the apoptotic mechanism of apicidin, we measured the expression levels of Bcl-2 family genes. Apicidin caused a clear down-regulation of the anti-apoptotic gene $\mathrm{Bcl}-2$, whereas the pro-apoptotic gene Bax expression was unchanged (Fig. 3C). We next performed densitometry analysis to determine the Bax/Bcl-2 ratios. As shown in Fig. 3D, apicidin treatment is associated with concentration-dependent increase in the $\mathrm{Bax} / \mathrm{Bcl}-2$ ratio.

\section{Apicidin induces caspases activity}

Our results clearly indicate that apicidin induces apoptosis in SK-OV-3 cells. Because we detected cleavage of the caspase substrate, poly (ADP-ribose) polymerase (PARP), we wished to measure the activity of caspases in response to apicidin treatment. We measured caspase-3, -8 and -9 activities with colorimetric substrates specific for each of
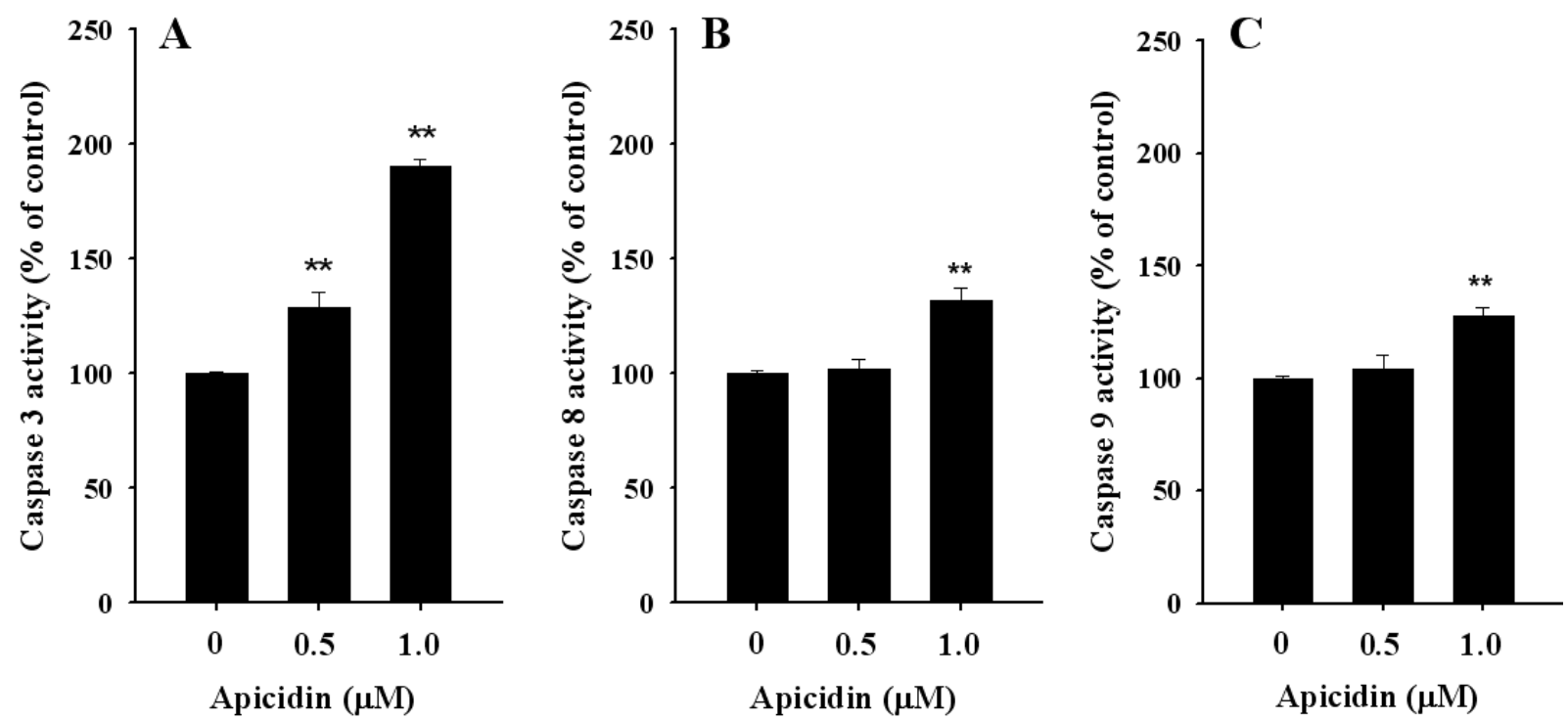

Fig. 4. Apicidin activates caspase-3, -8 , and -9 in SK-OV-3 cells. Cells were treated with the indicated concentrations of apicidin for 48 h. Cytosolic extracts of cells were prepared, and the activities of $(A)$ caspase-3, (B) caspase-8, and (C) caspase-9 were determined colorimetrically by using specific substrates as described in the Materials and Methods. Data are presented as the mean \pm S.D. from three similar experiments. $p$ values: ${ }^{* *}<0.01$ compared to untreated control.

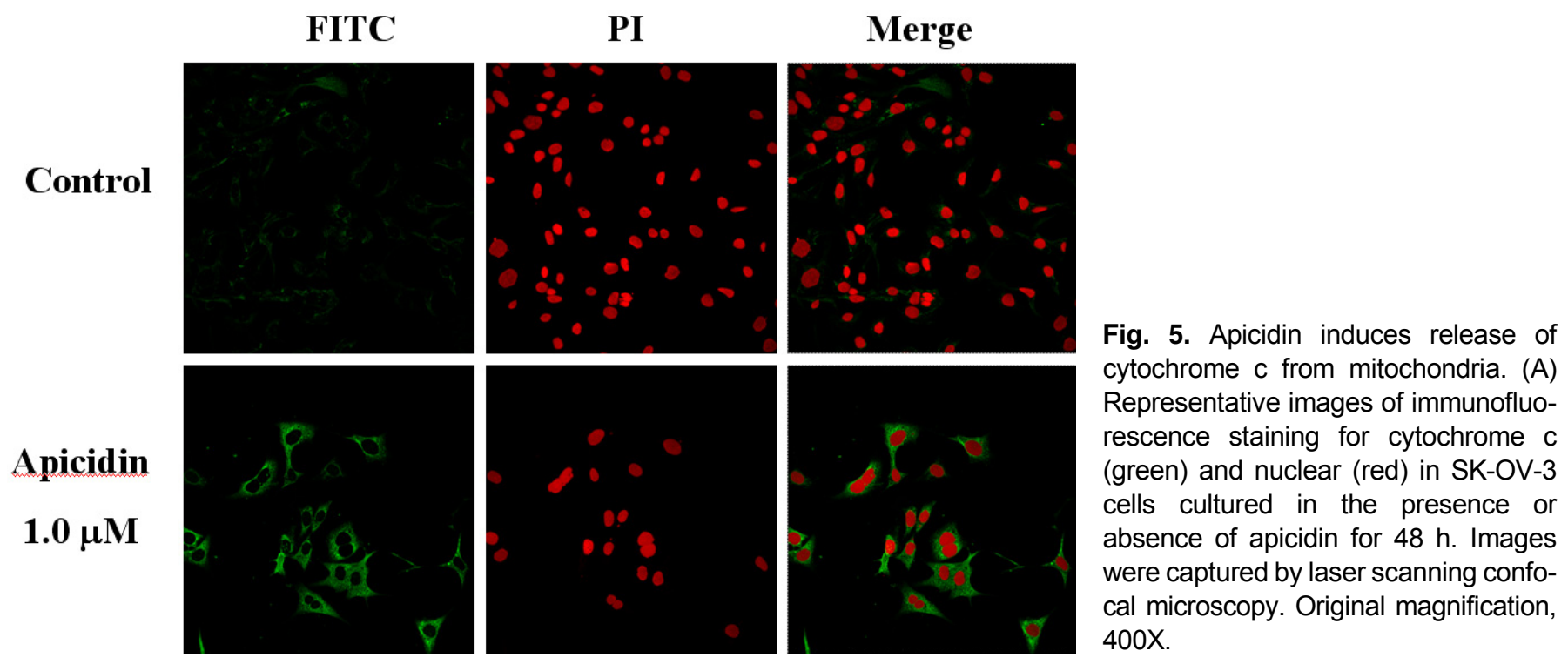


these enzymes. We found a significant and concentrationdependent activation of caspase- 3 in response to apcidin (Fig. 4A). In contrast, we were only able to detect a significant increase in caspase-8 and -9 activities in SK-OV-3 cells treated with $1.0 \mu \mathrm{M}$ apicidin (Fig. 4B, C).

\section{Apicidin induces the cytosolic release of cytochrome $c$}

To further investigate the mechanism of apoptosis induction by apicidin, we monitored release of cytochrome $\mathrm{c}$ from mitochondria in SK-OV-3 cells treated with apicidin for $48 \mathrm{~h}$. The localization of cytochrome $\mathrm{c}$ was monitored by immunofluorescence using the laser scanning confocal microscopy. As shown in Fig. 5, there were more greenstained points, indicating cytochrome $c$ released from mitochondria, into the cytoplasm of cells treated with apicidin (Fig. 5).

\section{DISCUSSION}

Apicidin is a novel cyclic tetrapeptide that possesses strong anti-proliferative activity in a variety of cancer cell lines (Han et al., 2002; Cheong et al., 2003; Im et al., 2008). We have examined the effects of apicidin on the inhibition of cell proliferation and apoptosis in human ovarian cancer cells. Our data show that apicidin markedly induced cell cycle arrest at G2/M phases and apoptotic cell death. In contrast with our observation, Han et al. (2000) showed that antiproliferative effects of apicidin on HeLa cells was accompanied by cell cycle arrest at $\mathrm{G} 1$ phase and inhibition of partially purified HDAC. Moreover, it has been suggested that DNA damage induces $\mathrm{G} 1$ arrest through the activation of the p53 pathway in non-transformed cells (Eastman, 2004). However, p53-defective tumor cells preferentially arrest in the S or G2/M phase (Sobola et al., 2006). Therefore, p53-null SK-OV-3 cells may fail to arrest in $\mathrm{G} 1$ phase and, instead, accumulate in the G2/M phase in response to apicidin.

Previous our data showed that psammaplin A (PsA), a new HDAC inhibitor, decreases the level of cyclin B1 and CDK1 at both the mRNA and protein levels. PsA also increased p21 and p27 expressions, both of play a critical role in G2/M cell cycle arrest and apoptosis in Ishikawa human endometrial cancer cells (Ahn et al., 2008). Furthermore, it has been reported that the anti-proliferative effects of HDAC inhibitors are believed to be mediated through the potent induction of $\mathrm{p} 21^{\text {cip } 1 / \text { war1 }}$. The up-regulation of p21 is essential for DNA damage-induced G1 or G2/M phases of the cell cycle arrest in human leukaemia, endometrial or ovarian cancer cell lines (Takai and Narahara, 2007; Petrella et al., 2008). Additionally, a recent study has shown that p27 is a major inhibitor of cyclin B1 and CDK1, and it can induce G2/M arrest (Baradari et al., 2006). Interestingly, Ueda et al. (2007) reported that apicidin markedly up-regulated the expression of $\mathrm{p} 21$ and p27, but not $\mathrm{p} 16$ and cyclin $\mathrm{B}$ expression. These data is partially associated with our result that apicidin-induced G2/M phase cell cycle arrest is due to both decreased cyclin B1/CDK1 expression and increased p21 and p27 expression (data not shown).

In this study, we found that apicidin potently induced apoptotic cell death in ovarian cancer cells. To further elucidate the mechanisms involved in apicidin-mediated apoptosis in human ovarian cancer cells, we analyzed the major factors of apoptosis pathways. The SK-OV-3 cells treated with apicidin displayed several features of apoptosis including a sub-G1 fraction of cells, DNA laddering, nuclear morphological changes, caspase activation, PARP cleavage and positive staining by TUNEL. In particular, we observed that caspase- 3 activation increased during apicidin-induced apoptosis and this was accompanied by cleavage of PARP, a known caspase-3 substrate. Previous studies have suggested that a caspase- 3 may be the potential key enzyme that mediates HDAC inhibitor induced apoptosis (Schepper et al., 2003; Shao et al., 2004). Additionally, we found that apicidin decreased the expression of $\mathrm{Bcl}-2$, an event that may disrupt mitochondrial membrane permeability and modulate the cytochrome $c$ release. Once released from the mitochondria, cytochrome $c$ interacts with apoptotic protease-activating factors (Apaf) and activates the execution caspases that subsequently lead to apoptosis (Green and Reed, 1998). Among these, active caspase- 3 is capable of cleaving various cellular proteins to cause apoptotic death (Wang, 2001).

Takai et al. (2004) showed that various several HDAC inhibitors such as SAHA, valproic acid, trichostatin A, and sodium butyrate induced apoptosis and decreased $\mathrm{Bcl}-2$ protein expression in endometroid adenocarcinoma cell lines. In chronic lymphocytic leukemia cells, the Bcl-2/Bax ratio was decreased as a consequence of decreased $\mathrm{Bcl}-2$ mRNA levels in response to treatment with valproic acid (Bokelmann and Mahlknecht, 2008). Thus, the Bcl-2/Bax ratio is an important cellular survival marker that correlates with responsiveness to drug therapy in vivo and in vitro. HDAC inhibitors may act through the transcriptional reactivation of dormant tumor suppressor genes. They also modulate expression of several other genes related to cell cycle, apoptosis, and angiogenesis (Shankar and Srivastava, 2008).

In conclusion, we found that apicidin has both anti-pro- 
liferative and pro-apoptotic activities in human ovarian cancer cells. The mechanism of apicidin-induced apoptotic pathway is likely mediated by induction of caspase-3 activation. These data suggest that apicidin is a potential anti-tumor agent and may be effective in the treatment of ovarian cancer.

\section{ACKNOWLEDGMENTS}

This work was supported by a Korea Research Foundation (KRF-2007-313-E00622) grant from the Korean Government.

\section{REFERENCES}

Ahn, M. Y., Jung, J. H., Na, Y. J. and Kim, H. S. (2008). A natural histone deacetylase inhibitor, Psammaplin $A$, induces cell cycle arrest and apoptosis in human endometrial cancer cells. Gynecol. Oncol. 108, 27-33.

American Cancer Society. Retrieved September 4, 2007, www. cancer.org.

Baradari, V., Huether, A., Höpfner, M., Schuppan, D. and Scherübl, H. (2006). Antiproliferative and proapoptotic effects of histone deacetylase inhibitors on gastrointestinal neuroendocrine tumor cells. Endocr. Relat. Cancer 13, 1237-1250.

Bokelmann, I. and Mahlknecht, U. (2008). Valproic acid sensitizes chronic lymphocytic leukemia cells to apoptosis and restores the balance between pro- and antiapoptotic proteins. Mol. Med. 14, 20-27.

Cheong, J. W., Chong, S. Y., Kim, J. Y., Eom, J. I., Jeung, H. K., Maeng, H. Y., Lee, S. T. and Min, Y. H. (2003). Induction of apoptosis by apicidin, a histone deacetylase inhibitor, via the activation of mitochondria-dependent caspase cascades in human Bcr-Abl-positive leukemia cells. Clin. Cancer Res. 9, 5018-5027.

Ding, Z., Yang, X., Pater, A. and Tang, S. C. (2000). Resistance to apoptosis is correlated with the reduced caspase-3 activation and enhanced expression of antiapoptotic proteins in human cervical multidrug-resistant cells. Biochem. Biophys. Res. Commun. 270, 415-420.

Eastman, A. (2004). Cell cycle checkpoints and their impact on anticancer therapeutic strategies. J. Cell Biochem. 91, 223231.

Green, D. R. and Reed, J. C. (1998). Mitochondria and apoptosis. Science 281, 1309-1312.

Han, J. W., Ahn, S. H., Park, S. H., Wang, S. Y., Bae, G. U., Seo, D. W., Kwon, H. K., Hong, S., Lee, H. Y., Lee, Y. W. and Lee, H. W. (2000). Apicidin, a Histone Deacetylase Inhibitor, Inhibits Proliferation of Tumor Cells via Induction of p21WAF1/Cip1 and Gelsolin. Cancer Res. 60, 6068-6074.

Im, J. Y., Park, H., Kang, K. W., Choi, W. S. and Kim, H. S. (2008). Modulation of cell cycles and apoptosis by apicidin in estrogen receptor (ER)-positive and-negative human breast cancer cells. Chem. Biol. Interact. 172, 235-244.

Kim, M. S., Son, M. W., Kim, W. B., Park, Y. I. and Moon, A. (2000). Apicidin, an inhibitor of histone deacetylase, prevents H-ras-induced invasive phenotype. Cancer Lett. 157, 23-30.

Kim, T. Y., Bang, Y. J. and Robertson, K. D. (2006). Histone deacetylase inhibitors for cancer therapy. Epigenetics 1, 14-23.

Kwon, S. H., Ahn, S. H., Kim, Y. K., Bae, G. U., Yoon, J. W., Hong, S., Lee, H. Y., Lee, Y. W., Lee, H. W. and Han, J. W. (2002). Apicidin, a histone deacetylase inhibitor, induces apoptosis and Fas/Fas ligand expression in human acute promyelocytic leukemia cells. J. Biol. Chem. 277, 20732080.

Liu, T., Kuljaca, S., Tee, A. and Marshall, G. M. (2006). Histone deacetylase inhibitors: Multi-functional anticancer agents. Cancer Treat. Rev. 32, 157-165.

Marks, P. A., Richon, V. M., Miller, T. and Kelly, W. K. (2004). Histone deacetylase inhibitors. Adv. Cancer Res. 91, 137168.

Mogal, A. and Abdulkadir, S. A. (2006). Effects of Histone Deacetylase Inhibitor (HDACi); Trichostatin-A (TSA) on the expression of housekeeping genes. Mol. Cell. Probes 20, 81-86.

Naora, H. and Montell, D. J. (2005). Ovarian cancer metastasis: integrating insights from disparate model organisms. J. Nat. Rev. Cancer 5, 355-366.

Petrella, A., D'Acunto, C. W., Rodriquez, M., Festa, M., Tosco, A., Bruno, I., Terracciano, S., Taddei, M., Paloma, L. G. and Parente, L. (2008). Effects of FR235222, a novel HDAC inhibitor, in proliferation and apoptosis of human leukaemia cell lines: role of annexin A1. Eur. J. Cancer 44, 740-749.

Schepper, S. D., Bruwiere, H. L. N., Verhulst, T., Steller, U., Andries, L., Woutesrs, W., Janicot, M., Artis, J., Heusden, J. V. (2003). Inhibition of histone deacetylases by chlamydocin induces apoptosis and proteasome-mediated degradation of surviving. J. Pharm. Exp. Therap. 304, 881-888.

Shankar, S. and Srivastava, R. K. (2008). Histone deacetylase inhibitors: mechanisms and clinical significance in cancer: HDAC inhibitor-induced apoptosis. Adv. Exp. Med. Biol. 615, 261-298.

Shao, Y., Gao, Z., Marks, P. A. and Jiang, X. (2004). Apoptotic and autophagic cell death induced by histone deacetylase inhibitors. Proc. Natl. Acad. Sci. U.S.A. 101, 18030-18035.

Sobola, H. D., Noymana, E. C., Kazanova, D., Figerb, A., Birkenfelda, S., Shapiroa, L. M., Benamouzig, R. and Arber, N. (2006). Celecoxib leads to G2/M arrest by induction of p21 and down-regulation of cyclin B1 expression in a p53-independent manner. Eur. J. Cancer 42, 422-426.

Takai, N., Desmond, J. C., Kumagai, T., Gui, D., Said, J. W., Whittaker, S., Miyakawa, I. and Koeffler, H. P. (2004). Histone deacetylase inhibitors have a profound antigrowth activity in endometrial cancer cells. Clin. Cancer Res. 10, 1141-1149.

Takai, N. and Narahara, H. (2007). Human endometrial and ovarian cancer cells: histone deacetylase inhibitors exhibit antiproliferative activity, potently induce cell cycle arrest, and stimulate apoptosis. Curr. Med. Chem. 14, 2548-2553.

Toh, Y., Yamamoto, M., Endo, K., Ikeda, Y., Baba, H., Kohnoe, S., Yonemasu, H., Hachitanda, Y., Okamura, T. and Sugimachi, K. (2003). Histone H4 acetylation and histone deacetylase 1 expression in esophageal squamous cell carcinoma. Oncol. Rep. 10, 333-338. 
Ueda, T., Takai, N., Nishida, M., Nasu, K. and Narahara, H. (2007). Apicidin, a novel histone deacetylase inhibitor, has profound anti-growth activity in human endometrial and ovarian cancer cells. Int. J. Mol. Med. 19, 301-308.

Wang, X. (2001). The expanding role of mitochondria in apopto- sis. Genes Dev. 15, 2922-2933.

Xu, W. S., Parmigiani, R. B., Marks, P. A. (2007). Histone deacetylase inhibitors: molecular mechanisms of action. Oncogene 26, 5541-5552. 